derived from the concept of organisms maintaining an optimal level of cortical arousal (e.g., Hebb, 1955). This position is based on the assumption that $\mathbf{S}$ obtains stimulus change as he scans the stimulus and that stimulus change produces arousal. When the opportunity to obtain stimulus change is denied by environmental conditions (such as by an enforced period of stimulus deprivation), S's arousal level descends from the optimal and continues to descend as deprivation continues. If one then assumes that the farther $S$ is from the optimal, the less stimulus change is needed to produce an increase in the level of arousal and that $\mathrm{S}$ continues to explore as long as the stimulus raises the level of arousal towards the optimal or maintains the optimal, the explanation of the current findings is straightforward. The long looking times that occur following long periods of deprivation stem from the ability of the stimulus to provide prolonged increases in the level of arousal because of S's distant position from the optimal. That is, when $S$ is far from the optimal, little stimulus change is needed to produce a given increase in arousal. Consequently, the arousal-producing potential of the stimulus is exhausted slowly. Similarly, the short looking times that occur following brief periods of deprivation stem from the inability of the stimulus to provide prolonged arousal because of S's close proximity to the optimal. That is, when $S$ is close to the optimal a large amount of stimulus change is needed to produce a given increase in arousal. Consequently, the arousal-producing potential of the stimulus is exhausted rapidly. The effects of stimulus complexity are explainable in a similar fashion: complex stimuli are looked at longer than simple stimuli because complex stimuli contain more arousal-producing properties and are therefore capable of either raising the arousal level or maintaining an optimal level for longer periods of tim $r$

\section{CANTOR, REFERENCES}

H., \& CANTOR, G. N. Functions relating children's observing behavior to amount and recency of stimulus familiarization. Journal of Experimental Psychology, 1966, 22. 859-863.

HEBB, D. O. Drives and the C. N. S. (conceptual nervous system). Psychological Review, 1955, 62, 243-254.

LECKART, B. T. Looking time: The effects of stimulus complexity and familiarity. Perception \& Psychophysics, 1966, 1, 142-144.

LECKART, B. T., KEELING, K. R., \& BAKAN, $P$. The effect of rate of presentation on free looking time. Perception \& Psychophysics, 1966, 1, 107-109.

LECKART, B. T., LEVINE, J. R., GOSCINSKI, C., \& BRAYMAN, W. Duration of attention: The perceptual deprivation effect. Perception \& Psychophysics, 1970, 7, 163-164.

SCHULTZ, D. P. Sensory restriction effects on behavior. New York: Academic Press, 1965. P. 145.

TENNISON, J. Duration of attention as a function of an adaptation to stimulus complexity. Unpublished dissertation, 1968, Ohio University.

\title{
Illusion decrement in intersecting line figures*
}

\author{
STANLEY COREN \\ The New School for Social Research, New York, N.Y. 10011 \\ and \\ JOAN S. GIRGUS
}

The City College of the City University of New York, New York, N.Y. 10031

This study tests the generality of illusion decrement using four illusion figures involving intersecting lines: the Zoellner, Poggendorff, Wundt-Hering, and Mueller-Lyer figures. Five minutes of inspection with testing at 1-min intervals led to significant decrement in all figures. The rate of decrement was the same for all figures. These data are consistent with a judgmental theory of geometric illusions.

Most theories of visual geometric illusions can be roughly categorized into one of two classes. The first class contends that visual illusions are created by peripheral distortion of the inputs (Chaing, 1968; Ganz, 1966; Békésy, 1967). The second class of theories suggests that judgmental

* We would like to thank Myra Agdern for her assistance in the collection of these data. variables provide the best explanation for the perceptual distortion (Carr, 1935; Piaget, 1969; Erlebacher \& Sekuler, 1969; Gregory, 1966).

Illusion decrement (i.e., the diminution of illusion magnitude with practice or inspection) is often the principal data offered in support of a central judgmental, as opposed to a peripheral optical or neural, mechanism (Over, 1968). Since a judgmental mechanism presumably reflects the manner in which an $O$ has learned to view certain stimuli in the past, it is fairly easy to imagine how such a mechanism could account for a decrement in illusion magnitude following inspection. It is somewhat more difficult to see how inspection might affect a physiological mechanism such as the optical or neural system in such a way that would lead to a decrement in illusion magnitude.

One major shortcoming of illusion decrement data is that it has been almost exclusively confined to the Mueller-Lyer figure, although some tentative evidence for decrement of the Poggendorff illusion has been offered by Cameron \& Steele (1905) and for decrement of a curvature illusion by Coren \& Festinger (1967). The occurrence of decrement in the magnitude of the Mueller-Lyer illusion is, however, well established (Judd, 1902; Lewis, 1908; Mountjoy, 1958; Day, 1962). Although the reasons for the decrease in illusion magnitude with practice are not yet clear, there are indications that information from erroneous saccadic eye movements made during inspection of the figure facilitates the process (Festinger, White, \& Allyn, 1968; Burnham, 1968).

Since decrement has been used as evidence for a judgmental mechanism in visual illusions, it is important to ascertain if decrement in illusion magnitude with inspection is a property of other illusion figures besides the Mueller-Lyer. The experiment reported below attempts to determine this for four illusion figures, each of which manifests a different type of distortion. One is an illusion of direction (the Zoellner), one an illusion of shape (the Wundt-Hering), one an illusion of displacement (the Poggendorff), and the last is an illusion of extent in which decrement is known to occur (the Mueller-Lyer). These particular illusions were chosen for investigation both because they manifest a variety of distortions and because they all contain intersecting line elements which are the optimal configurations for the operation of both optical aberrations (Chaing, 1968) and neural inhibitory interaction (Ganz, 1966; Békésy, 1967).

STIMULI AND APPARATUS

The illusion forms used in this experiment are represented in Fig. 1. The Zoellner Mlusion

The Zoellner illusion (Fig. 1A) was constructed with 2-mm-wide black lines. The three shafts were $11 \mathrm{~cm}$ long. Each of the intersecting lines was $3.5 \mathrm{~cm}$ long and crossed the shaft at an angle of $30 \mathrm{deg}$ from the vertical. The 


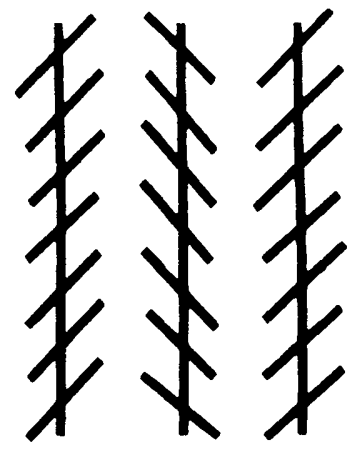

A
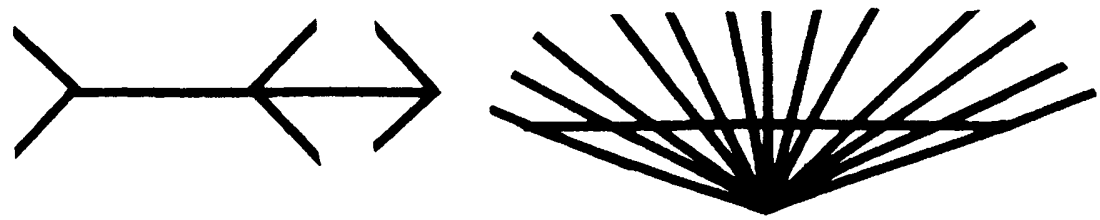

C

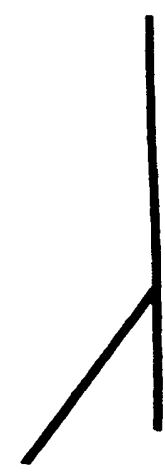

B

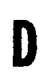

Fig. 1. The illusions used in this study: (A) the Zöllner illusion, (B) the Poggendorff illusion, (C) the Mueller-Lyer illusion, and (D) the Wundt-Hering illusion.

middle of the three figures was drawn on a sheet of clear acetate which pivoted around the center and which was laid on top of the heavy cardboard backing on which the flanking figures were drawn. The distance between the middle figure and each of the flanking figures was $1 \mathrm{~cm}$. Ss were told to adjust the sheet of acetate so that the shaft of the central figure appeared to be parallel to the shafts of the flanking figures. The degree of illusory tilt was then read to the nearest $0.5 \mathrm{deg}$ from an indicator mounted on the acetate overlay out of the S's view.

The Poggendorff Illusion

The Poggendorff illusion (Fig. 1B) was constructed with 2-mm black lines. The verticals were $11 \mathrm{~cm}$ in length. The transversals were $9 \mathrm{~cm}$ long and formed a 30-deg angle with the verticals. The verticals and the left-hand segment of the transversal were placed on a piece of cardboard. The right-hand segment of the transversal was mounted on a piece of clear acetate, which was placed on top of the cardboard. Ss were told to adjust the acetate up and down a vertical track until the two segments of the transversals appeared to be colinear. The setting could be read in millimeters from a concealed scale. The Mueller-Lyer nlusion

The Mueller-Lyer illusion (Fig. 1C) was constructed with 1 -mm black lines. The fixed shaft length was $8 \mathrm{~cm}$; the wings were $2 \mathrm{~cm}$ long and met the horizontal shaft at an angle of $45 \mathrm{deg}$. The right-hand half of the figure was adjustable in length and set in a tongue-and-groove arrangement constructed from heavy cardboard. Ss were told to set the right-hand shaft to apparent equality with the left-hand shaft. The magnitude of the illusion could be read from a millimeter scale affixed to the back of the movable section.

The Wundt-Hering Illusion

The Wundt-Hering illusion (Fig. 1D) was modeled after that used by Coren (1970a) and was constructed with 1-mm black lines. The horizontal line was $14 \mathrm{~cm}$ long. The lines intersecting the horizontal were separated by $10 \mathrm{deg}$. S could vary the apparent curvature of the horizontal test line by means of a variable prism through which he viewed the display. The variable prism was mounted in front of S's right eye, along with a Wratten No. 55 (green) filter, used to eliminate chromatic fringes. $S$ was told to set the test line to apparently straight. The magnitude of the illusion could be read in prism diopters from a scale attached to the prism mount.

SUBJECTS AND PROCEDURE

Forty undergraduate volunteers were recruited as Ss. Each $\mathrm{S}$ was assigned to one of the four illusions.

After the operation of the apparatus was explained to each $S$, an initial measurement of illusion magnitude was taken. Five more measurements of illusion magnitude were taken subsequently at 1-min intervals. Ss were instructed to "study the figure carefully" during the entire 5-min test and inspection period.

RESULTS AND DISCUSSION

Since the units of measurement of illusion magnitude differ among the four figures, they could not be used directly in the statistical computations. Therefore, the initial illusion strength was defined as $100 \%$ and all measurements of illusion magnitude are reported in percent illusion relative to the initial judgment. Figure 2 presents the mean percent illusion for each of the six judgments for each illusion separately. It is clear from this figure that all of the illusions showed a decrement. An analysis of variance reveals that the amount of decrement is significant over the 5 -min inspection period $(p<.01, F=6.23$, $\mathrm{df}=5 / 180)$. It is interesting to note that there are no significant differences between the four illusions in terms of amount of decrement $(F=0.42, \mathrm{df}=3 / 36)$. The similarity of the illusion decrements for the figures tested is further reflected in the absence of any significant interaction between the illusions and the

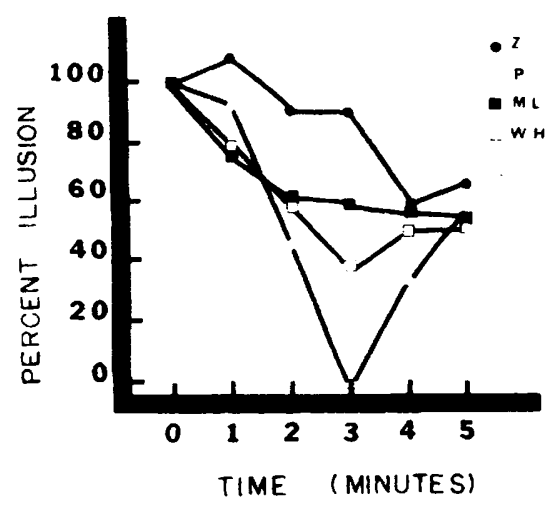

Fig. 2. Percentage of illusion is plotted against the inspection time in minutes for the Zölner illusion (Z), the Poggendorff illusion (P), the Mueller-Lyer illusion (ML), and the Wundt-Hering illusion (WH). 
inspection time $(F=0.84$, $\mathrm{df}=15 / 180$ ).

The major finding in these data is that all of the illusions tested, the Zoellner, Poggendorff, and Wundt-Hering, as well as the Mueller-Lyer, show a decrement with inspection. It is important to recall that these illusions were selected because they contain intersecting line elements and hence should be susceptible to explanation by theories based upon optical aberrations or lateral inhibitory interactions. Both of these theories of visual illusions have some difficulty explaining changes in illusion magnitude with inspection. Since judgmental theories do not have any such difficulties, these data may be taken as some support for a judgmental basis for the four illusions tested. Nonetheless, it is interesting to note that these illusions do not decrease to zero, but rather lose only about $45 \%$ of their strength. After $5 \mathrm{~min}$ of inspection, all four illusions are still significantly nonzero. Although it may be the case that with extended practice, the illusions would completely disappear, there seems to be some indication in Fig. 2 that the rate of decrement is tending toward an asymptote. Such a result would be consistent with a position which maintained that these illusions were multiply caused, with both a judgmental component and some peripheral distortion of the input. Some evidence for multiple causation in the Poggendorff and Mueller-Lyer illusions has already been offered by Coren $(1969,1970 \mathrm{~b})$.

One interesting aspect of these data ought to be mentioned. Since all of the figures tested seem to show a decrement to the same extent and at approximately the same rate, one is tempted to suggest that the same mechanism might underlie all of the illusions tested, or at least might mediate the decrement of these four illusions. It also suggests that data taken on any one of these figures may be generalizable to the others. Thus the vast literature on the factors which affect the rate of decrement in the Mueller-Lyer illusion may well be generalizable to other illusion figures containing intersecting lines.

\section{BÉKÉSY RFFERENCES \\ KESY, G. von. Sensory inhibition. Princeton, N.J: Princeton University Press, 1967.}

BURNHAM, C. A. Decrement of the Müller-Lyer illusion with saccadic and tracking eye movements. Perception \& Psy choph ysics, 1968, 3, 424-426.

CAMERON, E. H., \& STEELE, W. M. The Poggendorf illusion. Psychological Review Monograph Supplement, 1905 7(No. 29), 83-111.

CARR, H. A. An introduction to space perception. New York: Longmans, Green, 1935.

CHAING, C. A. A new theory to explain geometrical illusions produced by crossing lines. Perception Psychophysics, 1968, 3, 174-176.

COREN, S. The influence of optical aberrations on the magnitude of the Poggendorff illusion. Perception \& Psychophysics, 1969, 6, 185-186.
COREN, S. Lateral inhibition and the Wundt-Hering illusion. Psychonomic Science, 1970a, 18,341.

COREN, S. Lateral inhibition and geometric illusions. Quarterly Journal of Experimental Psychology, 1970b. 22, 274-278.

COREN, S., \& FESTINGER, L. An alternative view of the "Gibson normalization effect." Perception \& Psychophysics, 1967, 2, 621-626.

DAY, $R$. H. The effects of repeated trials and prolonged fixation on error in the Müller-Lyer figure. Psychological Monographs, 1962 , 76(14, Whole No. 533).

ERLEBACHER, A., \& SEKULER, R. Explanation of the Muller-Lyer illusion: Confusion theory examined. Journal of Experimental Psychology. 1969, 80, 462-467.

FESTINGER, L., WHITE, C. W.. \& ALLYN, $M$. R. Eye movements and decrement in the Muller-Lyer illusion. Perception \& Psychophysics, 1968, 3, 376-382.

GANZ, L. Mechanism of the figural aftereffects. Psychological Review, 1966. $73,128-150$.

GREGORY, R. L. Visual illusions. In B. M. Foss (Ed.), New horizons in psychology. Baltimore: Penguin Books, 1966. Pp. 68-96.

JUDD, C. H. Practice and its effects on the perception of illusions. Psychological Review, 1902, 9, 27-39.

LEWIS, E. O. The effect of practice on the perception of the Muller-Lyer illusion. British Journal of Psychology, 1908, 2. 294-306.

MOUNTJOY. P. T. Effects of exposure time and intertrial interval upon decrement to the Muller-Lyer illusion. Journal of Experimental Psychology, 1958, 56, 97-102.

OVER, R. Explanations of geometrical illusions. Psychological Bulletin, 1968. $70,545 \cdot 562$.

PIAGET, J. The mechanisms of perception. Translated by G. N. Seagrim. New York: Basic Books, 1969 . 